\title{
Can digitalization favour the emergence of innovative and sustainable business models? A qualitative exploration in the automotive sector
}

\author{
Chiara Acciarini
}

Department of Business and Management, Luiss University, Rome, Italy and Research Centre for Business Transformation, Luiss Business School, Rome, Italy

Fernando Borelli

Department of Business and Management, Luiss University, Rome, Italy

Francesca Capo

Department of Economics, Management and Statistics, University of Milan-Bicocca, Milan, Italy

Francesco Cappa

Department of Engineering, Campus Bio-Medico University, Rome, Italy and Department of Business and Management, Luiss University, Rome, Italy, and

\author{
Chiara Sarrocco
}

Department of Business and Management, Luiss University, Rome, Italy

\begin{abstract}
Purpose - The purpose of this paper is to explore the role of the digitalization phenomenon in the development of innovative business models that are sustainability oriented. Thus, the authors aim to understand whether the presence of digitalization forces companies to create, capture and deliver value in new ways, focusing on their social impact.

Design/methodology/approach - Through the analysis of a case study in the automotive sector, the authors provide evidence that both digitalization and sustainability need to be considered to adequately innovate business models. Moreover, these two dimensions are interrelated, and therefore digitalization sustains sustainability and vice versa.

Findings - By inductively investigating the evolutionary path along which companies tend to adapt their business models to digitalization and sustainability trends, the authors found that this innovative transformation needs to be as sustainable as possible in order to offer benefits to organizations, customers and society at large. Furthermore, the authors revealed that, at least in the automotive sector, companies and customers are aware of the remarkable consequences of digitalization; however, they are still uncertain regarding the actual adoption of new technologies.

Originality/value - The literature on business model innovation is quite extensive. However, the role of digitalization in developing sustainable business models to achieve a competitive advantage has been
\end{abstract}

(C) Chiara Acciarini, Fernando Borelli, Francesca Capo, Francesco Cappa and Chiara Sarrocco. Published by Emerald Publishing Limited. This article is published under the Creative Commons Attribution (CC BY 4.0) licence. Anyone may reproduce, distribute, translate and create derivative works of this article (for both commercial and non-commercial purposes), subject to full attribution to the original publication and authors. The full terms of this licence may be seen at http://creativecommons.org/licences/by/4.0/ legalcode

Digitalization and sustainable business models

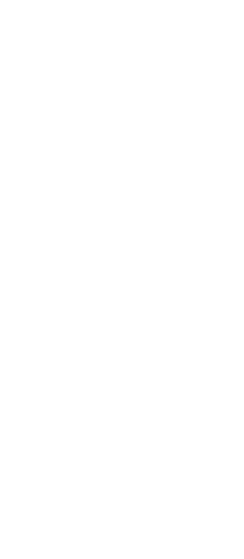


JSMA

15,3 overlooked. This study suggests that, within a specific context, forging a value network of stakeholders is helpful when innovating a business model with a sustainability orientation.

Keywords Digitalization, Business model innovation, Sustainability, Stakeholder engagement, Corporate strategy

Paper type Research paper

\section{Introduction}

The emergence of digital technologies and the increasing digitalization of the general public have been revolutionizing society and its equilibrium in recent years. The World Economic Forum expects that emerging technologies like cloud computing, big data analytics, the Internet of things and connected devices will be even more thoroughly adopted by 2025 . Current worldwide numbers make this evident, with over $25 \%$ of consumers using mobile devices for their purchases at least once a week and with a $160 \%$ increase in the frequency of digital purchases overall (World Economic Forum, 2020). Such changes are affecting the business environment in an extreme manner, allowing new players to emerge, and changing competitive equilibria.

Analyses have shown that more digitally mature companies have a revenue growth rate six times higher than their less digitalized competitors. The positive impact of this is not only in terms of economic performance; employees in the digitally advanced firms also reported a $50 \%$ greater index of well-being at work (Roland Berger and BDI, 2015). Indeed, digitalization may lead to a $20 \%$ improvement in efficiency and a $20 \%$ increase in revenues in the coming years (Parida et al., 2019). Despite the several advantages generated by technology, there are also some concerns, mainly related to the risk that automation could replace the existing workforce, that potential inequalities associated with the digital divide could increase and that health and security may suffer (Manyika et al., 2017). Notwithstanding these considerations, it has been argued that if Europe properly embraces digitization, by 2025, its manufacturing industry could enlarge its gross value by 1.25 trillion euros. On the other hand, the failure of the digitalization process could cause potential losses of up to 605 billion euros for European industries in the same timeframe (Roland Berger and BDI, 2015). Thus, digitalization plays a central role in triggering certain firms' strategic responses (Vial, 2019) when entering and competing in the market (OECD, 2018), and when reconfiguring existing business models (BMs) and business systems.

Moreover, digitalization is also affecting how companies manage their relationships with stakeholders (Agarwal et al., 2010; Majchrzak et al., 2016). In fact, another emerging aspect is the attention towards the three pillars of sustainability: economic, social and environmental (Cappa et al., 2020b). For instance, since 2016, the United Nations has been working on a structured agenda for sustainable progress with the aim of transforming our world by 2030 , and technology plays a predominant role in driving a more rapid achievement of these global goals (United Nations, 2020). In general, the potential effects of new digital technologies lead to a better alignment with societal needs. Indeed, automated machines can decrease emissions and waste (Bohnsack et al., 2014); furthermore, big data can provide advances in industries like healthcare, agriculture, energy, education and mobility, thus resulting in valuable resources being positively associated with a firm's performance (Cappa et al., 2020a).

Therefore, considering the pressing "grand challenges" that the society is facing, that is, open-ended global objectives such as secure, clean and efficient energy production (Foray et al., 2012; Kuhlmann, 2014), attention is centred not only on economic performance but also on the social and environmental pillars of sustainability. BlackRock, the world's largest asset manager, recently unveiled a big push into sustainable investing that recognizes the fact that investors and other stakeholders consider it crucial for companies to carefully manage their sustainability efforts. In fact, every company, as well as regulatory framework, is more 
attentive to environmental issues due to the overall negative effects that have had social implications (Intergovernmental Panel on Climate Change, 2014). Moreover, environmental and social concerns are critical issues to be integrated into a holistic view of corporate sustainability (Joyce and Paquin, 2016).

In such a turbulent context, characterized by digitalization and sustainability focuses, companies need to develop the right BM in order to create and capture value (Zott and Amit, 2017). Indeed, a BM can be defined "as the value logic of an organization in terms of how it creates and captures customer value and can be concisely represented by an interrelated set of elements that address the customer, value proposition, organizational architecture and economics dimensions" (Fielt, 2013, p. 86). Following the above reasoning, both digitalization and sustainability focuses are profoundly affecting BMs at present. However, thus far, the impact of digitalization and sustainability focuses on BMs has each been analysed separately. Some studies have focused on the former (Loebbecke and Picot, 2015; Mezger, 2014; Paulus-Rohmer et al., 2016; Rachinger et al., 2019) and others on the latter (Breuer et al., 2018; Geissdoerfer et al., 2018; Rantala et al., 2018). What has been overlooked is how the two can be considered jointly in allowing companies to develop a successful BM. In light of these considerations, the research question we addressed with this study is as follows: How can digitalization favour the adoption of sustainable, innovative BMs?

To answer our research question, we dissect the drivers of business model innovation (BMI) and how it is deeply affected by the digitalization trend and concern for sustainability pillars. We then investigate whether digitalization and sustainability together can jointly affect BMI through an inductive approach. We have selected the automotive sector as the context for our qualitative research because it is a relevant case study; it is a turbulent environment characterized by a number of innovations, and digitalization and sustainability are two significant trends for stakeholders. The outcomes of this study provide a new perspective on the impact that digitalization may have on the development of sustainability-oriented innovative BMs. These findings can help the managerial community to respond to digital disruption by considering new business model configurations that allow them to benefit their economic performance and also act on the increasing attention paid to environmental and societal issues. At the same time, this research provides theoretical contributions by expanding knowledge of the impacts produced by digitalization and the consequent orientation towards social consequences. In this manner, we integrate digitalization and BM theories from a sustainability perspective. Finally, we identify avenues that future researchers may use as a guide to answering pressing questions on digitalization and sustainable BMs.

This article is organized as follows. The first section provides a background and overview of BMI in the extant literature. Here, we review and discuss the various concepts and perspectives used to define BMI. Based on these, we introduce the concepts of digitalization and sustainability to explore potential interrelations with BMI. In the second section, we explain our qualitative method and present the findings of our analysis. In the final section, we discuss the results, the implication and the contribution of our study, both for academia and managerial practice.

\section{Conceptual framework}

\subsection{Business model and business model innovation definitions}

The definition of BM varies considerably across studies (Applegate, 2001; Dubosson-Torbay et al., 2002; Seelos and Mair, 2007; Shafer et al., 2005; Stewart and Zhao, 2000). Osterwalder and Pigneur, for instance, effectively and concisely defined the BM as "a conceptual tool composed by product innovation, infrastructure management, customer relationships and financial issues pillars"; in their view, BMs enable the definition of the basic logic of
Digitalization and sustainable business models

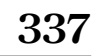


JSMA

15,3

organizations (Osterwalder and Pigneur, 2002). Applegate, in 2001, also defined a BM as a tool to describe how businesses use the Internet to interact with each other and how value is created for every stakeholder (Applegate, 2001). According to Teece (2010), a BM can be interpreted as a conceptual rather than financial model for a business (Teece, 2010). Zott et al. defined a BM as "the content, structure, and governance of transactions designed so as to create value through the exploitation of business opportunities" (Zott et al., 2011, p. 511). This expresses how transactions are related to activities and how transactions and activities can be seen as two different aspects of the same situation (Zott et al., 2011). A BM is also considered "the set of which activities a firm performs, how it performs them, and when it performs them" (Afuah and Tucci, 2001). Johnson et al. reported the main activities that BMs may embrace as being "training, development, manufacturing, budgeting, planning, sales and service" (Johnson et al., 2008). On the other hand, Mitchell and Coles underscored that a BM expresses its approach to giving products and services to customers and end users (Mitchell and Bruckner Coles, 2004), while Eisenmann et al. stated that it is related to the kind of services that companies supply to customers (Eisenmann et al., 2001) and to the activities that they execute to deliver those services. A BM is also considered a combination of elements between technological inputs and economic outputs (Chesbrough and Rosenbloom, 2002). $\mathrm{ABM}$ is the basis for the definition of structure in the value chain, where value is generated by defining a set of activities, from the selection of raw materials straight through to delivery to the final consumer, with value being added at each of the various steps. Thus, BMs highlight the way a company delivers value to its final end user at the proper cost. In sum, the application of BM concepts has garnered broad acceptance as a key driver for a firm's successful performance (Zott et al., 2011).

Overall, a BM can be defined as an organic matter since it aggregates processes, activities, resources and extensive networks of players which enable the company to define and implement its strategy. It represents the whole system of organizational and strategic solutions that allow firms to create and sustain competitive advantage over time by creating and delivering value to customers, and thereby converting payments received into profits (Zott and Amit, 2010). A BM defines the main players a firm interfaces with in terms of end consumers, suppliers and key partners. It also expresses which activities and processes are performed by the company. Financially speaking, BMs determine the amount and type of assets and resources needed and their cost structure, which defines the realization of their business activity as a whole and the resulting stream of revenues. Lastly, BMs shape the broad network of relationships and interconnections (including distribution channels) amongst the main roles within the firm and across industry borders, which are unavoidable for the firm's survival. These elements need to be hard to replicate since, along with an effective and efficient system architecture, they may lead the enterprise to establish a competitive advantage with respect to competitors.

In this context, the concept of business strategy, defined as the way in which a firm decides to compete in the market compared to its rivals, needs to be introduced (Meskendahl, 2010; Varadarajan and Clark, 1994). Even though the distinction between BM and business strategy is not clear, a BM is interpreted as a photograph of the firm's current position. Furthermore, the dynamic nature of the concept of BM becomes clear, since it concerns elements requiring constant interaction that can convey opportunities to create new value propositions by anticipating the evolution of the market. For this reason, it implies a holistic procedure through which managers should be able to modify their strategic approaches whether they appertain to already mature industries or to new businesses. BMs constitute a powerful tool that is able to highlight synergies among several of the firm's components, relating them to each other. Indeed, BMs allow companies to make projections for the future, by analysing and better defining threats and opportunities coming from the external environment while maintaining their flexibility to fit new opportunities well. Therefore, 
following an inside-out approach to the BM innovation process, the need to break the boundaries of a company becomes apparent, in order to allow knowledge, whether tacit or explicit, to flow smoothly within the company business, for monetary or non-monetary reasons. Examples can be seen in many companies that, during the pandemic, have converted their production processes in order to make masks or products that were initially scarce or urgently insufficient, such as hand sanitizer. This concept, based on total or partial openness towards external partners, brings with its numerous implications, starting from the very role a $\mathrm{BM}$ has in the commercialization of technology. In fact, technological evolution has developed in parallel fashion with the innovation of business structure, with increasing attention being paid to investments in R\&D and to environmental consciousness and societal issues.

As it is evident that BMs play a crucial role in organization success, there has been an increasing amount of analytical focus on how BMs can be innovated. Especially during this current period of turbulent change driven by digitalization and grand challenges, BMI may aid companies in maintaining and generating their competitive advantage over the years (Amit and Zott, 2012; Baden-Fuller and Haefliger, 2013; Casadesus-Masanell and Zhu, 2013; Chesbrough, 2010; Demil and Lecocq, 2010). Companies can achieve BMI by following new paths that define value propositions and generate and deliver value for customers, suppliers and partners (Bock, 2012; Casadesus-Masanell and Zhu, 2013; Gambardella and McGahan, 2010; Teece, 2010). Two main approaches have taken shape for understanding BMIs. On the one hand, the first approach shows that different BMs can be achieved through an incremental process of small changes to the elements within the model (Amit and Zott, 2012; Demil and Lecocq, 2010; Dunford et al., 2010; Landau et al., 2016; Velu, 2016). On the other hand, innovative BMs can be marked out during a revolutionary process by displacing the existing BM (Iansiti and Lakhani, 2014; Landau and Bock, 2013). Currently, the two main trends that affect BMs the most are digitalization and sustainability orientation, and these require changes on the part of organizations, customers, suppliers and all other stakeholders.

\subsection{Business model innovation in the digital era}

The digitalization of the business environment and of the general public has directly affected corporate culture, business processes and purchasing behaviours. We refer to digitalization as "the way in which many domains of social life are restructured around digital communication and media infrastructures" (Brennen and Kreiss, 2015, p. 1). Indeed, it is possible to talk about digitalization as a concept that implies the use of digital technology, and it concerns the way society has had to adapt to this progress.

The reason behind this interest in digitalization is due to its role as an enabler of BMIs that make it possible to generate novel ways to create and deliver value to customers (Rachinger et al., 2019). An example of an innovative BM is that of Netflix, which has benefitted from digitalization and thus been able to transform the way we spend our free time. The adoption of technologies has enabled the company to shape its new BM. Using a structured algorithm on the consumer data collected, it has been possible to create a streaming service tailored to the needs of each end user. More generally, digitalization offers opportunities to influence BMIs in several ways: optimizing the existing BM (e.g. in terms of costs), transforming the existing BM (e.g. reconfiguring the established business) and developing a new BM (e.g. developing new products and services) (Rachinger et al., 2019).

\subsection{Business model innovation for sustainability}

It has been shown that, while developing BMs, companies need to take into account every stakeholder and, more generally, society as a whole (Short et al., 2013; Stubbs and Cocklin, 2008; Upward and Jones, 2016; Weber and Kratzer, 2013). Consequently, companies are more
Digitalization and sustainable business models

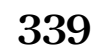


JSMA

15,3

340

and more focused on addressing societal issues to support their sustainable development goals (SDGs). Sustainability, in this sense, has been playing an increasingly predominant role in BMIs, with the creation of sustainable BMs (Zott and Amit, 2010). This has led to the recent definition provided by authors (Pieroni et al., 2019; Rantala et al., 2018) who have interpreted sustainable BMs as a modification of the conventional BM concept, with certain characteristics and goals added to it. Moreover, they either (1) incorporate concepts, principles or goals that aim for sustainability, or (2) integrate sustainability into their value proposition, value creation and delivery activities, and/or value capture mechanisms. The main aim was to lead firms to be more sustainable economic systems and to integrate sustainability topics into organizations and to develop sustainability ambitions (Harun et al., 2013; Stubbs and Cocklin, 2008; Wells, 2013). At present, sustainable BMs are increasingly considered to be a source of competitive advantage (Porter and Kramer, 2011; Nidumolu et al., 2009). Thus, some studies affirm that sustainable BMs may in some cases overcome the traditional BM concept much like sustainable competitive advantage has overcome competitive advantage (Grant, 2010). Indeed, to orientate a firm towards sustainability in a systematic way, an innovative BM must embed societal value into products and services. Therefore, sustainability constitutes a driver of BMI to achieve sustainable development (Schaltegger et al., 2012). In general, firms need to reimagine their BMs for sustainability and to reshape existing business ecosystems to support initiatives with societal impacts. To summarize, business strategy should consider the scale and complexity of BMI for sustainability and the need to develop a new BM through experience (Evans et al., 2017).

\subsection{Business model innovation in the digital era for sustainability}

For the above-mentioned reasons, it can be seen that both digitalization and sustainability affect BM structure in its evolutionary path. Therefore, we contend that, on the one hand, there is the necessity to adapt organizational structure to new tendencies by innovating the $\mathrm{BM}$ as a result of recent digitalization trends; on the other hand, the transformation should follow a path as sustainable as possible. In the following sections, we inductively investigate how such an approach is actually implemented in a relevant case study.

\section{Methods}

The organization we studied operates in the automotive sector in Europe, and we shall call it DeltaS. DeltaS offers vehicles, accessories and spare parts, as well as repair, maintenance, financing and insurance services, and it serves customers worldwide. We selected the automotive sector as a context for analysis because it is a turbulent and dynamic environment, with several breakthrough innovations like electric mobility, autonomous vehicles, automated factories and ridesharing rapidly transforming the industry, thus determining a shift from traditional to innovative business models. Moreover, almost every firm, from car manufacturers and dealers to automotive service companies, is expanding its digital initiatives as well as increasing the number of its strategic partnerships, which are mainly focused on electrification and shared mobility. This identifies another key characteristic of this industry that makes it a perfect fit for our investigation: the need to embrace sustainability thanks to sharing economy. The sharing model has rapidly expanded at a global scale by involving millions of users who have very positive attitudes towards sustainable trends and thus are willing to adopt "mobility as a service solution" (MaaS) by combining different transport forms into a single on-demand service (Cruz and Sarmento, 2020; Gerwe and Silva, 2020). Finally, although increasing competition in the automotive sector is mainly associated with the complexity of the MaaS landscape, it is also associated with the speed of growth of new entrants in this market, as they force incumbents to innovate their business models. 
To answer our research question, we chose a target that would be best able to inform us on how digitalization is forcing companies operating within the industry to change their business models in terms of a more considered understanding of sustainability issues. We collected data using (1) semi-structured one-on-one interviews (Flick, 2009; Glaser and Strauss, 1967) and (2) archival data consisting of written and electronic documentation. We relied on the interviews as the main source of data, and we then integrated the analysis with surveys and some additional archival data. In particular, we conducted in-depth interviews with a DeltaS dealer manager and with one of the firm's external partners by way of the director of the Information and Communication Technologies (ICT) research and sustainable mobility centre located in the Lazio region of Italy. Through the adoption of a standardized interview protocol, these initial interviews included questions about competitive positioning, performance variations deriving from the development of new technologies, sustainability trends and how to address them, dealer-customer relationships and the consequences of the COVID-19 outbreak. In addition, we carried out a survey to identify customers' reasons for adopting new trends and, consequently, to analyse their consumer purchasing behaviour. The online survey was composed of 32 questions sent to 60 respondents in the period from June to July 2020. Despite the fact the target of our analysis constitutes a small percentage of the market, it is still significant and representative if combined with the other data available. To summarize, we were able to collect promising insights on the organization side (DeltaS), the external side (ICT research and sustainable mobility centre) and the customer side (respondents to the survey).

\section{Findings}

To analyse our data we followed the model of recent research in the field (Grodal et al., 2020), and from our interviews and archival data we generated a number of initial theoretical categories that we eventually refined and stabilized. This process of moving from initial to tentative and finally to stabilized categories that included the main insights of our interviews and archival data (Grodal et al., 2020) allowed us to conduct a more rigorous analysis that could build on our theory, moving from findings close to our informants to more generalizable layers. We then collected the results in a data structure, following an earlier model (Gioia et al., 2013). Specifically, our data structure allows us to identify two main theoretical dimensions (digitalization and sustainability) and also to show how these two dimensions are interrelated. Our findings have enabled us to flesh out not only the two key pillars that companies need to focus on in order to build an innovative business model but also how one pillar (i.e., digitalization) can sustain the other (i.e., sustainability). In the following section we detail our data structure and the process we followed to eventually identify our main theoretical dimensions.

First, from our interviews, it emerged that in regard to digitalization, informants recognized that "Many people are adapting to the new way of doing business"; for example, "[...] customers have a large number of innovative tools that allow them to find all the information they need [...]".

In this sense, advanced technologies like consumption algorithms increase the likelihood that sophisticated tools for lead generation and management can be developed. The information asymmetries of markets are reduced, thanks to the removal of barriers between them, through the expansion of globalization, which has allowed the widespread growth of the Internet in emerging and developing economies as well.

This leads us to the definition of a new player: the digitally conscious consumer. This became very clear in the words of our informant, who seemed to be aware of the new opportunities offered by digital platforms that allow them to have a completely different shopping experience than in the past.
Digitalization and sustainable business models 
JSMA

15,3

We have recently witnessed the birth of a new figure: the digital consumer, who is no longer just a millennial born into an already digitized context, but also the mature individual who witnessed and personally experienced digital transformation. (Interview with a DeltaS dealer manager, August 28th, 2020)

Although nowadays many online platforms are leveraging online selling to provide cars to consumers (e.g. Amazon), our results show that many consumers are still unwilling to buy luxury goods such as a car online. Notwithstanding many consumers may be reluctant to buy cars online, the majority of them still believe that the use of online platforms to collect information is extremely useful and that a visit to a car dealership is of great help. Such consumer willingness to embrace digital technology is leveraged by DeltaS when strategizing future paths to take. In the words of our informant:

There is no turning back, taking advantage of the customer's open-mindedness to new technologies (...) we want to continue on this path by implementing the digital services offered and extending them also to after-sales and administration (Interview with a DeltaS dealer manager, August 28th, 2020)

In conjunction with the increase in touchpoints that allow interaction between company and customer, facilitating the entire process for both, this has led to the creation of a single dimension within which online and offline coexist, triggering a significant transformation of the entire customer experience. Our informant clearly explained the evolution the company is experiencing, moving from demand for products to demand for experiences.

We are witnessing the transition from the discovery of the car in the traditional showroom to the customization and purchase of the product through digital platforms. (Interview with a DeltaS dealer manager, August 28th, 2020)

Once again, digital consumers who embrace this new scenario acknowledge the fact that digital technologies may provide numerous advantages for them and for businesses. For example, consulting before the purchase of a vehicle takes, on average, $30 \mathrm{~min}$ less if the customer has already visited the car manufacturer's website. This is just one of the most significant advantages for the dealer, who is thus able to manage several people on the same day.

In addition, the possibility for dealers to offer a more suitable and targeted product is simplified. Thanks to the adoption of new technologies, dealers can also send WhatsApp mini spots on technical content to explain specific features or services (e.g., driving safety systems). Together with the "possibility of reaching potential customers outside their geographical area" and thus increasing the company's profitability, a potential advantage is the ability to promote vehicles and services "[. . .] with just one click".

In this sense, entering markets considered profitable because they are characterized by market demand that is more inclined to adopt digital choices is facilitated by the speed of transmission of not only information and resources but also of the finished products themselves. The online market, therefore, makes it possible to reach, in a far-reaching manner, all or almost all population groups, stimulating interest in a product whose characteristics and peculiarities may not have been known before. The conversion rate guaranteed by online practices is a measure that is in fact continuously monitored by companies, and thanks to activities like public relations, direct marketing and trade marketing, companies are able to reach customers in an extensive way, offering them personalized and targeted content to meet their specific needs and also awaken the latent needs of the traditional consumer. The digital dimension has in fact led to the creation of ad hoc content that is personalized and capable of reaching the largest number of users in the least time possible, and of guaranteeing their experience, as documented, as much as possible. In this way companies touch the hearts of their customers, making them feel special and 
giving them special attention, such as discounts or promotions, that help them retain their loyalty in the long term.

In sum, the initial theoretical dimension that has emerged from our findings allows us to say that new digitally conscious consumers, an increased focus of customer demand on experiences and the ability of firms to leverage digital tools to enter new, unexplored and possibly profitable markets have triggered the need for companies to adopt digital business models.

Additionally, another key theoretical dimension emerged from our interviews: the need for companies to embrace sustainability within their business models. Indeed, our informants recognized that - especially during the COVID-19 outbreak - "there was the need to ensure the best possible experience for customers, with particular attention to social issues". Customers' sensibility towards sustainability is well reflected in their increasing willingness to embrace an economy based on sharing, rather than possession, particularly when it comes to means of transportation and commuting:

Customers themselves do not consider it essential to own a vehicle, and car-sharing is typically preferred to public transport. (Interview with a DeltaS dealer manager, August 28th, 2020)

According to our informants, in view of "renewed sensibility towards social and environmental concerns", DeltaS needs to embrace strategies that focus on sustainability yet also make the most of the opportunities arising from the use of digital technology. Moreover, and at the same time, they must handle their resources and reach their business goals without ever losing sight of social and environmental issues. Additionally, to develop strategies that can embrace digital tools and dispel customer concerns regarding sustainability and social impact, the imperative for DeltaS seems to be that of working together with other players in the ecosystem. This call for a "community perspective",- in which multiple stakeholders cooperate, the harmonization of the work of different branches and the needs for external players turned out to be - in the words of our informants - the key to offering a lasting value proposition. This finding clearly emerges from the following quote:

One of the results we have reached, even though it had already been discussed extensively in the literature, is the need for cooperation between the company and the surrounding area, the latter being a set of partners with whom to work together in order to be competitive. (Interview with the director of an ICT research and sustainable mobility centre located in Lazio, Italy. August 25th, 2020)

In light of this, especially at a time of crisis, the dealers felt a "strong sense of networking" by receiving the support they needed from DeltaS to adopt tools and processes for remote customer management. Modern companies belong, indeed, to an ecosystem, a multisystem network, which sometimes also takes the form of a hyper-network often connected by multidimensional layers of community. Companies must necessarily become part of a network in which, together with other organizations or public and private operators, they can share resources and information and elaborate adequate strategies to respond to the increasing demand for social and environmental care. To do so, right from the start, cooperation proved to be the winning tool.

Specifically, in order to conduct research into sustainable mobility issues, it was necessary to increase the number of private stakeholders such as companies and interlocutors in order to cooperate and collaborate. (Interview with the director of an ICT research and sustainable mobility centre located in Lazio, Italy. August 25th, 2020)

The need for DeltaS to interact on a day-to-day basis with other players in the ecosystem, in order to develop a strong sense of networking with local players and territories as well, highlights the importance for companies of what we define as "community engagement". The adoption of such a collaborative approach and of openness towards subjects outside the
Digitalization and sustainable business models 
JSMA

15,3

344

organization may also have implications in terms of profitability and economic returns. As a matter of fact, many studies have shown that one's own knowledge, if enriched by external impulses, produces higher levels of performance, thanks to the broader availability of guaranteed resources.

Considering that the aim is to guarantee the best value proposition for the client, the former "cannot be traced back to the simple sum of the value of individual contributions but is partly contained in the network of experience and values that links the actors who have voluntarily and actively participated in its creation" (Pilotti and Ganzaroli, 2006).

The two theoretical dimensions identified as key to building innovative business models, specifically "embracing digitalization" and "embracing sustainability", are not stand-alone dimensions. On the contrary, what emerges from our data is that, by leveraging digital tools and technologies, companies may develop more socially and environmentally oriented strategies, thus also incorporating sustainability in their business models.

In our interviews, informants claimed that, by adopting innovative technologies like lithium-free batteries, materials that are harmful for territories can be managed. Although these technologies are costly, they can be leveraged to minimize companies' environmental impact, thus embracing the sustainability concerns raised by both customers and other players in the ecosystem.

The most futuristic and difficult option to implement - due to the high cost of the technology - is a hydrogen car that is able to achieve autonomy levels equivalent to those of cars with internal combustion systems but without using polluting batteries. (Interview with the director of an ICT research and sustainable mobility centre located in Lazio, Italy. August 25th, 2020)

Furthermore, although a number of concerns were voiced regarding battery autonomy, our informants agreed that the use of specific technologies can help companies to save energy and build more environmentally friendly mobility models:

Things are improving (in environmental terms) because batteries today are increasingly better performing and, with the same energy content, they are smaller, lighter and faster to charge (...). This makes cars increasingly usable, from a range of $100 \mathrm{~km}-500 \mathrm{~km}$ for new generation models. (Interview with the director of an ICT research and sustainable mobility centre located in Lazio, Italy. August 25th, 2020)

In sum, our analysis highlights the two key pillars, digitalization and sustainability, around which companies need to build their business models in order to be innovative and successful in a long-term perspective, but it also provides evidence of how they are interrelated. Indeed, by incorporating and exploiting digital tools, companies can also foster sustainability and embrace the social and environmental concerns raised by customers and society at large. Figure 1 summarizes our data structure and the theoretical dimensions emerging from our analysis.

\section{Discussion}

Our study aimed to explore the role of the digitalization in the adoption of sustainable innovative BMs. Specifically, we grounded our arguments on the observation that - in the event of disruptive transformations like digitalization - companies are forced to redefine and innovate their BMs to adequately respond to external changes. In particular, we predicted that companies that intend to innovate are also the ones that pay more attention to the three pillars of sustainability, namely the environmental, social and economic one. This is because these companies are increasingly aware that the sustainability of their BMs is a key driver for success. Therefore, we present the environmental and social concerns as critical pillars to be integrated into the corporate sustainability concept, in addition to the economic performance. This allows us to show how, by juxtaposing the 
- "Many people are adapting to the new way of doing business"; for example, "[...] customers have a large number of innovative tools that allow them to find all the information they need"

- Customer awareness of digital technologies

- There is no turning back, taking advantage of the customer's mental openness to new technologies (...) we want to continue on this path by implementing the digital services offered and also extending them to after-sales and administration'

- We are witnessing the transition from the discovery of the car in the traditional showroom to the customization and purchase of the product through digital platforms

- Need to activate additional service to facilitate and foster customer experience

- Digital allows firms to reach customers located in different geographical areas

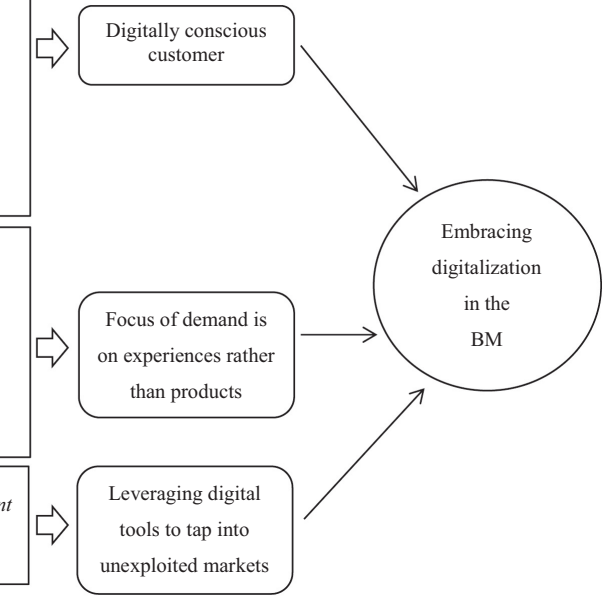

- Customers' sensibility shifts towards sustainability

- Customers are increasingly adopting sharing models of transportation and commuting

- Need to provide customers with experiences that take social issues into account

- Companies need to work together with other players in the ecosystem

- It is key for companies to adopt a strong sense of networking

- Cooperate with local protagonists and territories

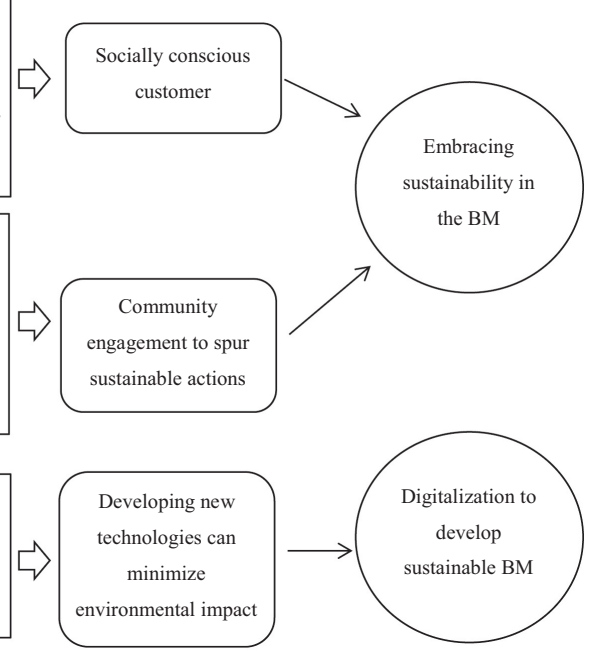

Figure 1.

Data structure

- Developing hydrogen cars to reduce pollution

- Exploiting lighter, faster, and better performing batteries to promote energy savings

Digitalization and sustainable business models

345

reproduced from Gioia

et al. (2013)

methodology

environmental and social pillar to the economic one, companies can fully incorporate the concept of sustainability, paying attention to all the three elements that characterize truly sustainable companies.

Through the analysis of the DeltaS case study in the automotive sector, we detected the sense of integration and action between the parties on sustainable development. Especially, while we collected evidence that managers are aware of the need to cooperate and communicate within the network, we understood that customers are more focused on the digitalization's experience and benefits. In fact, the data collected revealed several benefits 
JSMA

15,3

346

associated with the adoption of new technologies (e.g., reduction of waiting times, higher interaction), and the sustainability aspect is emphasized mostly in relation to the opportunity to build a valuable network of stakeholders within the community. The attention paid to respect the natural environment, the fundamental provision of infrastructure and the help provided to communities in which the organization operates represent the principal objectives to achieve economic, social and environmental needs.

On the one hand, the growing development of digitally enabled BMs highlights the need to be more open and connected; on the other hand, a strong sense of community emphasizes the essential relationship between companies, partners and their territory. Adequate levels of understanding of digitalization, combined with a sustainability orientation, allow companies to innovate their business models and create, capture and deliver value not only for themselves and for their customers, but also for society at large (Figure 2). In so doing, we advance the scientific understanding of BMI in light of digitalization and sustainability, and we also provide managers with indications on which benefits can be brought about.

\subsection{Implications}

Our study contributes to understanding the intersection between BMI, digitalization and sustainability. Specifically, the results of this research increase our theoretical knowledge on the definition of BMI and on the relevance of networking strategies. Similarly, the study also has implications for managers who intend to innovate BMs and to consider not only economic but also societal and environmental impacts. In particular, the results suggest that establishing a network of multiple stakeholders is crucial for managing and providing sustainability efforts in the context of digitalization. Therefore, the interrelation among the parties enables the creation of innovative BMs. Moreover, even though the investments in advanced technologies are costly, several benefits can be achieved at organizational, individual and societal levels. Finally, the interaction between companies and the environment, and the associated impacts can be considered to effectively design and implement sustainable development policies. For example, the provision of new environmental grants and other financial incentives could allow businesses to remain

Figure 2 .

Proposed model for innovative and sustainable business models, our elaboration

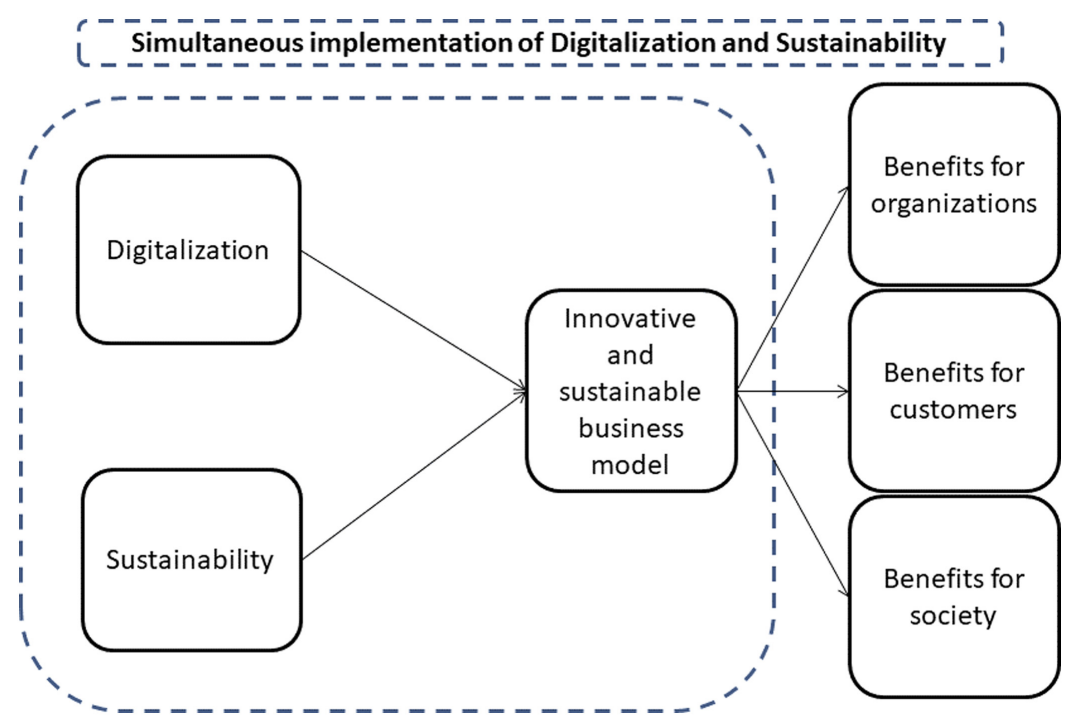


profitable while changing their business model. Moreover, the promotion of positive sustainable case studies can represent the starting point to work more rapidly on present and future international policies and initiatives.

\subsection{Limitations and future research}

Although the contributions of this study are noteworthy, several limitations need to be elaborated. Future researchers may examine whether the impact of digitalization on BMI with a sustainable orientation appears to be more contagious or significant in certain sectors than in others. In fact, since our study is focused on the automotive sector, future analyses on innovative and sustainable BMs can consider additional contexts in order to measure and compare the related effects. Moreover, the specific role of partners within the community should be emphasized in order to explore how every player contributes to the innovation of BMs, with particular attention paid to societal issues. Then, the evolution of the stakeholders' relationship over time can be explored with the aim to identify the most influential elements characterizing this cooperation and to understand what its possible threats are. In this sense, a broad dissertation on the most successful set of actions to involve the stakeholders into the sustainability pillars can be fruitful. With regard to the societal and environmental concerns, the analysis of determined objectives and the main actions implemented represent a promising area of study.

Furthermore, since changing customers preferences will increasingly push buying of vehicles online, and despite our results suggesting that most of the customers of the dealer are still reluctant to buy online their vehicle, future studies can explore this transition from the online purchase of small items (e.g., books) to bigger ones. In this case, future discussions can be based on the opportunities for dealers and car makers to shift to online sales for gathering more data and developing a better understanding of customer behaviours.

In addition, certain advanced technologies can be studied with the aim of identifying possible impacts in terms of more sustainable behaviours. In particular, which kinds of technology have a greater influence on the likelihood that companies will implement sustainable behaviours in the long term? Under which conditions of change? Finally, promising research and managerial insights could derive from an analysis of the impact of BMIs on specific SDGs, as reported by the United Nations. Therefore, what specific SDGs are most affected by the innovation of BMs?

\section{Conclusions}

The advent of digitalization constitutes an enormous challenge for companies, customers and society at large. Currently, companies tend to innovate their BMs in order to capture numerous opportunities associated with the use of new technologies. Our analysis of the DeltaS case study underscores the fact there is a significant gap between technological knowledge and real technology adoption. Therefore, specific initiatives and measures to support comprehension of digitalization and its potential effects on society should be developed within the community. In the digital era, the real value of BMI is the creation of a dense network of interconnections between companies, customers and partners who apply, exchange and expand digital solutions. This collaborative spirit plays a crucial role in transforming the competitive advantage into sustainability.

\section{References}

Afuah, A. and Tucci, C. (2001), Internet Business Models and Strategies, McGraw, New York.

Agarwal, R., Gao, G.G., DesRoches, C. and Jha, A.K. (2010), "The digital transformation of healthcare: current status and the road ahead”, Information Systems Research, Vol. 21 No. 4, doi: 10.1287/ isre.1100.0327. 
JSMA 15,3
Amit, R. and Zott, C. (2012), "Creating value through business model innovation", MIT Sloan Management Review, Vol. 53 No. 3, pp. 41-49.

Applegate, L.M. (2001), "E-business Models: making sense of the Internet business landscape", Information Technology and the Future Enterprise: New Models for Managers.

Baden-Fuller, C. and Haefliger, S. (2013), "Business models and technological innovation”, Long Range Planning, Vol. 46 No. 6, doi: 10.1016/j.lrp.2013.08.023.

Bock, B. (2012), "Social innovation and sustainability; how to disentangle the buzzword and its application in the field of agriculture and rural development", PloS One, Vol. 114, pp. 1-7.

Bohnsack, R., Pinkse, J. and Kolk, A. (2014), "Business models for sustainable technologies: exploring business model evolution in the case of electric vehicles", Research Policy, Vol. 43 No. 2, doi: 10. 1016/j.respol.2013.10.014.

Brennen, S. and Kreiss, D. (2015), "Digitalizaiton and digitization”, Culture Digitally.

Breuer, H., Fichter, K., Lüdeke-Freund, F. and Tiemann, I. (2018), "Sustainability-oriented business model development: principles, criteria and tools", International Journal of Entrepreneurial Venturing, Vol. 10 No. 2, doi: 10.1504/IJEV.2018.092715.

Cappa, F., Oriani, R., Peruffo, E. and McCarthy, I.P. (2020a), "Big data for creating and capturing value in the digitalized environment: unpacking the effects of volume, variety and veracity on firm performance", The Journal of Product Innovation Management, Vol. 38 No. 1, pp. 49-67, doi: 10.1111/jpim.12545.

Cappa, F., Rosso, F. and Capaldo, A. (2020b), "Visitor-sensing: involving the crowd in cultural heritage organizations", Sustainability, Vol. 12 No. 4, p. 1445, doi: 10.3390/su12041445.

Casadesus-Masanell, R. and Zhu, F. (2013), "Business model innovation and competitive imitation: the case of sponsor-based business models”, Strategic Management Journal, Vol. 34 No. 4, doi: 10. 1002/smj.2022.

Chesbrough, H. (2010), "Business model innovation: opportunities and barriers", Long Range Planning, Vol. 43 Nos 2-3, doi: 10.1016/j.lrp.2009.07.010.

Chesbrough, H. and Rosenbloom, R.S. (2002), "The role of the business model in capturing value from innovation", Industrial and Corporate Change, Vol. 11, pp. 354-363.

Cruz, C.O. and Sarmento, J.M. (2020), “Mobility as a service' platforms: a critical path towards increasing the sustainability of transportation systems", Sustainability, Vol. 12 No. 16, p. 6368.

Demil, B. and Lecocq, X. (2010), "Business model evolution: in search of dynamic consistency", Long Range Planning, Vol. 43 Nos 2-3, doi: 10.1016/j.1rp.2010.02.004.

Dubosson-Torbay, M., Osterwalder, A. and Pigneur, Y. (2002), "E-business model design, classification, and measurements”, Thunderbird International Business Review, Vol. 44 No. 1, doi: 10.1002/tie.1036.

Dunford, R., Palmer, I. and Benveniste Jodie, J. (2010), "Business model replication for early and rapid internationalisation. The ING direct experience”, Long Range Planning, Vol. 43 Nos 5-6, doi: 10. 1016/j.lrp.2010.06.004.

Eisenmann, T.R., Hallowell, R. and Tripsas, M. (2001), Internet Business Models: Texts and Cases, McGraw-Hill, New York, NY.

Evans, S., Vladimirova, D., Holgado, M., Van Fossen, K., Yang, M., Silva, E.A. and Barlow, C.Y. (2017), "Business model innovation for sustainability: towards a unified perspective for creation of sustainable business models", Business Strategy and the Environment, Vol. 26 No. 5, doi: 10. 1002/bse.1939.

Fielt, E. (2013), "Conceptualising business models: definitions, frameworks and classifications", Journal of Business Models, Vol. 1, pp. 85-105.

Flick, U. (2009), Introdução à pesquisa qualitativa (3a ed., J.E. Costa, Trad.), Artmed, São Paulo (Obra original publicada em 1995). 
Foray, D., Mowery, D. and Nelson, R. (2012), "Public R\&D and social challenges: what lessons from mission R\&D programs?”, Research Policy, Vol. 41 No. 10, pp. 1697-1792.

Gambardella, A. and McGahan, A.M. (2010), "Business-model innovation: general purpose technologies and their implications for industry structure", Long Range Planning, Vol. 43 Nos 2-3, doi: 10.1016/j.lrp.2009.07.009.

Geissdoerfer, M., Vladimirova, D. and Evans, S. (2018), "Sustainable business model innovation: a review”, Journal of Cleaner Production, Vol. 198, doi: 10.1016/j.jclepro.2018.06.240.

Gerwe, O. and Silva, R. (2020), "Clarifying the sharing economy: conceptualization, typology, antecedents, and effects", Academy of Management Perspectives, Vol. 34 No. 1, pp. 65-96.

Gioia, D.A., Corley, K.G. and Hamilton, A.L. (2013), "Seeking qualitative rigor in inductive research", Organizational Research Methods, Vol. 16 No. 1, doi: 10.1177/1094428112452151.

Glaser, B. and Strauss, A. (1967), The Discovery of Grounded Theory. 1967, Weidenfield \& Nicolson, London.

Grant, L.K. (2010), "Sustainability: from excess to aesthetics", Behavior and Social Issues Volume, Vol. 19, pp. 7-47.

Grodal, S., Anteby, M. and Holm, A.L. (2020), "Achieving rigor in qualitative analysis: the role of active categorization in theory building", Academy of Management Review, Epub ahead of print 13 April. doi: 10.5465/amr.2018.0482.

Harun, N.A., Rashid, A.A. and Alrazi, B. (2013), "Measuring the quality of sustainability disclosure among the Malaysian commercial banks", World Applied Sciences Journal, Vol. 28, doi: 10.5829/ idosi.wasj.2013.28.efmo.27026.

Iansiti, M. and Lakhani, K.R. (2014), "8 ways to build collaborative teams", Harvard Business Review, Vol. 92 No. 11, pp. 0017-8012.

Intergovernmental Panel on Climate Change (2014), Climate Change 2014 Mitigation of Climate Change. doi: 10.1017/cbo9781107415416.

Johnson, M.W., Christensen, C.M. and Kagermann, H. (2008), "Reinventing your business model", Harvard Business Review, pp. 50-59.

Joyce, A. and Paquin, R.L. (2016), "The triple layered business model canvas: a tool to design more sustainable business models", Journal of Cleaner Production, Vol. 135 No. 1, doi: 10.1016/j. jclepro.2016.06.067.

Kuhlmann, S. (2014), "The challenge of addressing grand challenges", European Union Framework Programme Horizon, Bruxelles, 2020.

Landau, C. and Bock, C. (2013), "Value creation through vertical intervention of corporate centres in single business units of unrelated diversified portfolios - the case of private equity firms", Long Range Planning, Vol. 46 Nos 1-2, doi: 10.1016/j.lrp.2012.11.002.

Landau, C., Karna, A. and Sailer, M. (2016), "Business model adaptation for emerging markets: a case study of a German automobile manufacturer in India”, R\&D Management, Vol. 46 No. 3, doi: 10. 1111/radm.12201.

Loebbecke, C. and Picot, A. (2015), "Reflections on societal and business model transformation arising from digitization and big data analytics: a research agenda", The Journal of Strategic Information Systems, Vol. 24 No. 3, doi: 10.1016/j.jsis.2015.08.002.

Majchrzak, A., Lynne Markus, M. and Wareham, J. (2016), "Designing for digital transformation: lessons for information systems research from the study of ICT and societal challenges", MIS Quarterly: Management Information Systems, Vol. 40, doi: 10.25300/MISQ/2016/40.

Manyika, J., Lund, S., Chui, M., Bughin, J., Woetzel, J., Batra, P., Ko, R. and Sanghvi, S. (2017), Jobs Lost, Jobs Gained: What the Future of Work Will Mean for Jobs, Skills, and Wages, McKinsey \& Co.

Meskendahl, S. (2010), "The influence of business strategy on project portfolio management and its success - a conceptual framework", International Journal of Project Management, Vol. 28 No. 8 , doi: 10.1016/j.ijproman.2010.06.007. 
JSMA 15,3

Mezger, F. (2014), “Toward a capability-based conceptualization of business model innovation: insights from an explorative study", R\&D Management, Vol. 44 No. 5, doi: 10.1111/ radm.12076.

Mitchell, D.W. and Bruckner Coles, C. (2004), "Business model innovation breakthrough moves", Journal of Business Strategy, Vol. 25 No. 1, doi: 10.1108/02756660410515976.

Nidumolu, R., Prahalad, C.K. and Rangaswami, M.R. (2009), "Why sustainability is now the key driver of innovation", Harvard Business Review, available at: https://hbr.org/2009/09/whysustainability-is-now-the-key-driver-of-innovation.

OECD (2018), Conference on Implications of the Digital Transformation for the Business Sector, London.

Osterwalder, A. and Pigneur, Y. (2002), "Constructing the e-economy an e-business model ontology for modeling e-business", BLED 2002 Proceedings, Article 2.

Parida, V., Sjödin, D. and Reim, W. (2019), "Reviewing literature on digitalization, business model innovation, and sustainable industry: past achievements and future promises", Sustainability, Vol. 11 No. 391, pp. 1-18.

Paulus-Rohmer, D., Schatton, H. and Bauernhansl, T. (2016), "Ecosystems, strategy and business models in the age of digitization - how the manufacturing industry is going to change its logic", Procedia CIRP, Vol. 57, doi: 10.1016/j.procir.2016.11.003.

Pieroni, M.P.P., McAloone, T.C. and Pigosso, D.C.A. (2019), "Business model innovation for circular economy and sustainability: a review of approaches", Journal of Cleaner Production, Vol. 215, doi: 10.1016/j.jclepro.2019.01.036.

Pilotti, L. and Ganzaroli, A. (2006), "Rileggere il marketing", Strategie Informative e Gestione Della Conoscenza, pp. 1-395, ISBN-10 : 8813263066.

Porter, M.E. and Kramer, M.R. (2011), “Creating shared value”, Harvard Business Review, pp. 62-77, available at: https://hbr.org/2011/01/the-big-idea-creating-shared-value.

Rachinger, M., Rauter, R., Müller, C., Vorraber, W. and Schirgi, E. (2019), "Digitalization and its influence on business model innovation", Journal of Manufacturing Technology Management, Vol. 30 No. 8, doi: 10.1108/JMTM-01-2018-0020.

Rantala, T., Ukko, J., Saunila, M. and Havukainen, J. (2018), "The effect of sustainability in the adoption of technological, service, and business model innovations", Journal of Cleaner Production. doi: 10.1016/j.jclepro.2017.10.009.

Roland Berger and BDI (2015), The Digital Transformation of Industry. How Important Is It? Who are the Winners? What Must Be Done Now?

Schaltegger, S., Lüdeke-Freund, F. and Hansen, E.G. (2012), "Business cases for sustainability: the role of business model innovation for corporate sustainability", International Journal of Innovation and Sustainable Development, Vol. 6 No. 2, doi: 10.1504/IJISD.2012.046944.

Seelos, C. and Mair, J. (2007), "Profitable business models and market creation in the context of deep poverty: a strategic view", Academy of Management Perspectives, Vol. 21 No. 4, doi: 10.5465/ AMP.2007.27895339.

Shafer, S.M., Smith, H.J. and Linder, J.C. (2005), "The power of business models”, Business Horizons, Vol. 48 No. 3, doi: 10.1016/j.bushor.2004.10.014.

Short, S.W., Rana, P., Bocken, N.M.P. and Evans, S. (2013), "Embedding sustainability in business modelling through multi-stakeholder value innovation", IFIP Advances in Information and Communication Technology, Vol. 397, doi: 10.1007/978-3-642-40352-1_23.

Stewart, D.W. and Zhao, Q. (2000), "Internet marketing, business models, and public policy”, Journal of Public Policy and Marketing, Vol. 19 No. 2, doi: 10.1509/jppm.19.2.287.17125.

Stubbs, W. and Cocklin, C. (2008), "Conceptualizing a 'sustainability business model”, Organization and Environment, Vol. 21 No. 2, doi: 10.1177/1086026608318042. 
Teece, D.J. (2010), "Business models, business strategy and innovation”, Long Range Planning, Vol. 43 Nos 2-3, doi: 10.1016/j.lrp.2009.07.003.

United Nations (2020), Take Action for the Sustainable Development Goals.

Upward, A. and Jones, P. (2016), "An ontology for strongly sustainable business models: defining an enterprise framework compatible with natural and social science", Organization and Environment, Vol. 29 No. 1, doi: 10.1177/1086026615592933.

Varadarajan, P.R. and Clark, T. (1994), "Delineating the scope of corporate, business, and marketing strategy”, Journal of Business Research, Vol. 31 Nos 2-3, doi: 10.1016/0148-2963(94)90074-4.

Velu, C. (2016), "Evolutionary or revolutionary business model innovation through coopetition? The role of dominance in network markets", Industrial Marketing Management, Vol. 53, pp. 124-135.

Vial, G. (2019), "Understanding digital transformation: a review and a research agenda”, The Journal of Strategic Information Systems, Vol. 28 No. 2, doi: 10.1016/j.jsis.2019.01.003.

Weber, C. and Kratzer, J. (2013), "Social entrepreneurship, social networks and social value creation: a quantitative analysis among social entrepreneurs", International Journal of Entrepreneurial Venturing, Vol. 5 No. 3, doi: 10.1504/IJEV.2013.055291.

Wells, P. (2013), "Sustainable business models and the automotive industry: a commentary", IIMB Management Review, Vol. 25 No. 4, doi: 10.1016/j.iimb.2013.07.001.

World Economic Forum (2020), Digital Transformation: Powering the Great Reset, Geneva.

Zott, C. and Amit, R. (2010), "Business model design: an activity system perspective", Long Range Planning, Vol. 43 Nos 2-3, doi: 10.1016/j.lrp.2009.07.004.

Zott, C. and Amit, R. (2017), "Business model innovation: how to create value in a digital world", GfK Marketing Intelligence Review, Vol. 9 No. 1, doi: 10.1515/gfkmir-2017-0003.

Zott, C., Amit, R. and Massa, L. (2011), "The business model: recent developments and future research", Journal of Management, Vol. 37 No. 4, doi: 10.1177/0149206311406265.

\section{About the authors}

Chiara Acciarini is $\mathrm{PhD}$ candidate in management at Luiss University, Rome, Italy, where she also held cum laude the master's degree in management. She is research fellow at the Research Centre for Business Transformation (ReBooT), Luiss Business School, and she is teaching assistant to Corporate Strategies and Hotel Management, Luiss University. She supports the Global Family Business Management Executive Programme, Luiss Business School and the Management and Governance of Family Firms master's course, Luiss University. Her research interests include strategic change and business model innovation. Chiara Acciarini is the corresponding author and can be contacted at: cacciarini@luiss.it

Fernando Borelli graduated cum Laude in management from Luiss Guido Carli University of Rome (Italy), where he is teaching assistant of several courses such as advanced corporate finance, corporate governance, corporate strategy, business strategy and entrepreneurship and venture capital. He is also a business analyst of Arthur D. Little, a top strategy consulting firm. His main research interests are in the areas of strategy, entrepreneurship and innovation. His works have been accepted in prestigious international refereed conferences such as Academy of Management and Euram.

Francesca Capo is an assistant professor in management at the Department of Economics, Management and Statistics at University of Milano-Bicocca. She earned a PhD in management from Luiss Guido Carli University and has been visiting scholar at ESSEC Business School (France), Catolica Business School (Portugal) and Ross School of Business (Michigan, US). Among her main research interests are institutional change, institutional logics, hybrid organizations and social enterprises.

Francesco Cappa is an assistant professor at the Department of Engineering, Campus BioMedico University of Rome (Italy), and an adjunct professor at the Department of Business and Management, Luiss Guido Carli University of Rome (Italy). He has been a visiting researcher at New York University Tandon School of Engineering (USA) and Pace University Seidenberg School of Computer Science (USA). His main research interests are in the areas of innovation and sustainability. His papers have appeared in prestigious international refereed journals such as Research Policy, Journal of Product Innovation Management, Small Business Economics, IEEE Transactions on Engineering Management,
Digitalization and sustainable business models 
JSMA

15,3

352

Strategic Organization, Journal of Environmental Management, Business Horizons, Computers in Human Behavior, Information Technology for Development, Quarterly Review of Economics and Finance, Digital Business and Sustainability.

Chiara Sarrocco graduated in business and management from Luiss University, Rome. She worked as retail sales consultant at Nicola Prezioso S.r.l., and she currently works as e-mobility manager in the automotive sector. Her main research interests are in the areas of sustainable business models and digital transformation issues.

For instructions on how to order reprints of this article, please visit our website: www.emeraldgrouppublishing.com/licensing/reprints.htm Or contact us for further details: permissions@emeraldinsight.com 